\title{
El Concepto del Crimen de Odio por Homofobia en América Latina. Datos y discursos acerca de los homicidios contra las minorías sexuales: el ejemplo de México
}

\author{
The Concept of Homophobic Hate Crime in Latin America. Data and statements \\ about homicides against sexual minorities: the example of Mexico
}

\author{
O Conceito de Crime de Ódiopor Homofobia na América Latina. Dados e \\ discursos relacionados aos homocídios contra as minorias sexuais: o exemplo \\ do México
}

\author{
Renaud René Boivin \\ Instituto Francés de Urbanismo - México \\ renoboivin@yahoo.es
}

\section{Resumen}

El artículo examina los usos del concepto de 'crimen de odio por homofobia' en América Latina y su recepción en México, a partir de los datos recopilados acerca de los homicidios cometidos en contra de las minorías sexuales en la ciudad de México desde los años 1990. Se describe la metodología empleada para la selección de casos, y se repasan los distintos criterios empleados por las organizaciones de lucha contra la violencia homicida cometida contra las minorías sexuales: la saña no sería un criterio de identificación del odio, sino la brutalidad física una categoría dominante en los discursos y las representaciones de la prensa que ha servido a establecer los primeros registros de crímenes anti-LGBT.

Palabras-Clave: Violencia; Minorías Sexuales; Ciudad de México; Homofobia; Crímenes de Odio; Homicidios.

\section{Abstract}

The article examines the use of the term 'homophobic hate crime' in Latin America and its reception in Mexico, from the data collected on homicides committed against sexual minorities in Mexico City from 1990s. The methodology for the selection of cases is described, and the different criteria used by organizations to combat the murderous violence committed against sexual minorities are reviewed: the anger would not be a criterion for identification of hate, but the physical brutality as a dominant category in the discourses and representations of the press, that had served to establish the first records of anti-LGBT crimes.

Keywords: Violence; Sexual Minorities; Mexico City; Homophobia; Hate Crimes; Homicides. 
El Concepto del Crimen de Odio por Homofobia en América

Latina. Datos y discursos acerca de los homicidios contra las

minorías sexuales: el ejemplo de México

\section{Resumo}

O artigo examina os usos do conceito de 'crime de ódio' por homofobia na América Latina e sua recepção no México, a partir dos dados recompilados acerca dos homicídios cometidos contra minorias sexuais na cidade do México, desde os anos de 1990. Se descreve a metodologia empregada para a seleção dos casos e se repassam os dintintos critérios empregados pelas organizações de luta contra a violência homicida cometida contra minorias sexuais: a ira não seria um critério de identificação de ódio, senão a brutalidade física uma categoria dominante nos discursos e representações da imprensa que tem servido ao estabelecimento dos primeiros registros de crimes anti LGBT.

Palavras-Chave: Violência; Minorías Sexuais; Cidade do México; Homofobia; Crímes de Ódio; Homicídios.

\section{Introducción}

Las estadísticas constituyen un elemento esencial para explicar los fenómenos sociales y una manera de difundir dichas explicaciones de manera simple a la opinión pública. La información estadística nos provee de modelos para abordar las complejidades del mundo, sin embargo, el discurso común tiende a pensar las estadísticas como datos objetivos de la realidad: ahora bien, como bien recuerdan Joel Best (2000) o Laurent Thévenot (2006), las estadísticas son productos de la actividad de categorización humana, es decir, construcciones sociales que sirven a menudo para la manipulación política.

La noción de crimen de odio por homofobia, crecientemente utilizada en América Latina para categorizar a los homicidios motivados por el prejuicio homofóbico, ha sido objeto de mucha confusión en los análisis acerca de los asesinatos contra personas lesbianas, gays, bisexuales, transexuales y travestis o $\mathrm{HSH}^{1}$. Fue poco discutida entre los autores y las organizaciones que la emplearon para estudiar y denunciar tales homicidios. En México, inspirándose directamente del concepto jurídico estadounidense, los activistas refieren casos de homicidios que no están vinculados con el odio y la intolerancia hacia las minorías sexuales. Los inestables, imprecisos y poco rigurosos criterios de selección de posibles casos de ser crímenes de odio perpetuados por homofobia, generan a su vez una gran imprecisión en los hallazgos obtenidos, algunos cálculos habiendo integrado asesinatos de personas cuyas prácticas y orientaciones sexogenéricas son desconocidas.

En el marco de un proyecto financiado por el Instituto de Desarrollo Social, al actualizar el listado de casos de homicidios de personas LGBT de la Comisión Ciudadana Contra los Crímenes de Odio por Homofobia $(\mathrm{CCCCOH})$, pude percatarme de algunas de las incidencias negativas que conllevan los criterios elegidos para seleccionar las notas de prensa con las cuales se registraron los casos de homicidios cometidos contra las personas LGBT y HSH. A continuación tras describir la recepción del concepto jurídico de 'crimen de odio por homofobia' en América Latina, se analizan los criterios de selección de casos utilizados, así como los datos obtenidos a través de aquella metodología, enmarcando dichos resultados en el contexto discursivo militante en respuesta a la homofobia institucional de los medios de comunicación, de los servicios de seguridad pública $\mathrm{y}$ del sistema judicial. 
Veremos que al incorporarse al lenguaje militante y académico, el concepto de crimen de odio por homofobia pierde fuerza $y$ profundidad para describir la violencia simbólica y social que padecen las personas LGBT y HSH asesinadas en México.

\section{El Origen del Concepto de 'Crimen de Odio por Homofobia'}

El concepto de 'crimen de odio' tiene sus orígenes en Estados Unidos en los años 80 , cuando, a raíz de conflictos étnicoraciales, las minorías reclamaron una nueva legislación que sistematizase las estadísticas sobre los crímenes de carácter religioso o étnico-racial. El debate sobre la violencia racial se empezó entonces a organizar en torno al establecimiento de un sistema estadístico adecuado para conocer con mayor profundidad, cuantificar y tratar el problema, dando lugar a una legislación específica: a partir de la ley federal 'Hate Crime Statistics Act' (1990), los 'crímenes por prejuicio' vienen definiéndose cómo 'crimes that manifest evidence of prejudice based on race, religion, sexual orientation, or ethnicity, including where appropriate the crimes of murder (...), (...) intimidation.' Dicha ley, reforzada en 1994 por la 'Violent Crime Control and Law Enhancement Act', otorgó un reconocimiento jurídico a este tipo de crímenes, confiando al FBI la tarea de centralizar la información acerca de los datos de homicidios motivados por el odio y el prejuicio, sean de orden racial, religioso o basados en la orientación sexual y la identidad de género. Desde entonces, con el fortalecimiento de las políticas de identidad, el uso de la noción de crimen de odio se generalizó ${ }^{2}$, dando pie a un discurso alarmista sobre la 'epidemia' de dichos crímenes, los cuales, pese a una mayor penalización, estarían aumentando. (JACOBS y POTTER, 2001).
Las modificaciones acaecidas en la agenda pública estadounidense influyeron a su vez en la adopción del término en otros países americanos y anglosajones. El nuevo enfoque influyó menos en Europa, el debate americano siendo sustituido por una mayor criminalización del discurso de incitación al odio, racial particularmente. En las legislaciones europeas, la homofobia, al igual que el prejuicio étnico-racial o religioso, constituye un agravante para cualquier delito $^{3}$, y, por consiguiente, las agresiones basadas en el odio homofóbico son castigadas por la justicia con mayor severidad cuando se comprueba que el móvil está ligado al prejuicio o a la intolerancia. Aún así, a principios de siglo, el empuje por la defensa de los derechos de las minorías sexuales por un lado, y el recrudecimiento de las violencias contra la población LGBT en algunos países del este y del sur del continente por otro, justificaron el refuerzo de la legislación.

\section{Recepción e Institucionalización del Término en América Latina}

A diferencia de los países europeos, en donde la discusión tiende a centrarse en la violencia racista, en América Latina la noción de 'crimen de odio' se adoptó principalmente para describir a los homicidios anti-LGBT. Por las fechas de las publicaciones, se deduce que la introducción del concepto ha sido protagonizada por el Grupo Gay de Bahía, dirigido por Luiz Mott, historiador de la Universidad de Salvador, quien coordinó los distintos informes del grupo sobre las violencias hacia las minorías sexuales de Brasil desde mediados de los años noventa. El Grupo Gay de Bahía empezó conservando notas encontradas en la prensa nacional acerca de agresiones anti-LGBT desde su formación, en 1980. A partir de entonces, el grupo publicó en su boletín una lista de 
dichos asesinatos con el nombre, la edad, la profesión y la causa de muerte de las víctimas. En su informe de 1996, escrito en inglés, los militantes recopilan todos los casos de homicidios hallados: se trataría del mayor material recolectado en América Latina, reflejando los asesinatos de 1260 travestís, homosexuales, bisexuales y lesbianas ejecutados entre 1963 y 1994 (MOTT, 1996), a los cuales el Grupo Gay de Bahía denomina "crímenes homofóbicos" aunque sin definir la noción ni remitirse de forma específica al concepto jurídico estadounidense.

En México, la introducción del término se debe principalmente a actores ligados al llamado movimiento gay. La organización Letra S., que publica un suplemento semanal sobre sexualidad, salud sexual y VIH-sida en La Jornada, a partir de varios casos emblemáticos su informe de tales como el de Efraín Cruz García y de conocidos activistas matados en años anteriores, junto con familiares de algunas víctimas y abogados ${ }^{4}$, inicia $^{5}$ entonces un trabajo de concientización y denuncia, el cual cristalizará en 1998 con la formación de la Comisión Ciudadana Contra los Crímenes de Odio por Homofobia $(\mathrm{CCCCOH})$, formada por personalidades de organizaciones gays, de lucha anti-sida y del ámbito académico, tales como Alejandro Brito, Carlos Bonfil, Carlos Monsiváis, Rodolfo Millán y Marta Lamas 6 . El término es retomado a principios del siglo en algunos artículos científicos, sin mucha problematización del concepto ni gran aterrizaje empírico en el contexto específico del campo sexual masculino mexicano.

En el resto de América Latina, la denominación "crímenes de odio por homofobia", o "por orientación sexual", no aparece hasta mediados de los años 2000. Por ejemplo, la Comunidad Homosexual Argentina (CHA), un grupo pionero en la documentación de violaciones a los derechos humanos hacia las personas LGBT, no empieza a usar el término hasta el año 2005. En el Perú, el Colectivo Raíz 2 y el Movimiento Homosexual de Lima (MHOL), empujados por la publicación de los informes de Amnistía International (2001), ILGA (2001) y de la Comisión de la Verdad y Reconciliación en Perú (2003), no lo integran a su vocabulario hasta entonces:

Desde el 31 de mayo de 1989 -explican los integrantes del MHOL (2004)- en que un grupo de seis integrantes del grupo subversivo Movimiento Revolucionario Tupac Amaru (MRTA) mató a balazos a ocho miembros de la comunidad LGTB, se han realizado una serie de actividades conmemorativas $\mathrm{y}$ denuncias [...]. [En 2003], el MHOL presentó el Retablo de la Memoria TLGB, donde se daba cuenta de los hechos acontecidos [...]. Se inscribieron los nombres de las personas que habían sido asesinadas por el odio homo/lesbo/transfóbico desde 1989 hasta 2003, llegando a más de 100 víctimas $[\ldots] .^{7}$

Ahora bien, al adoptar el término 'crimen de odio', los militantes de Perú se refieren a un contexto político preciso de exterminio y represión policial, y no a la violencia interpersonal: mientras que en el Primer Encuentro Nacional LGTB, en junio de 2004, todavía prima un uso político de la expresión -los activistas debaten sobre 'Violencia política, crímenes de odio, memoria y reparación'- su sentido irá modificándose a partir del informe del MHOL de 2005 (Bracamonte, 2006), ampliándose a todo tipo de crímenes contra personas LGBT o susceptibles de serlo. A partir de 2005, esta confusión entre asesinatos políticos, ejecuciones extrajudiciales y otros crímenes 
anti-LGBT no motivados por el odio, entre la violencia interpersonal y la violencia institucional, se hace constante en los discursos militantes latinoamericanos, orientados por una suerte de carrera estadística que serviría para evidenciar el nivel local de homofobia cultural ${ }^{8}$ y así solicitar urgentes medidas y políticas públicas para combatir la discriminación contra las minorías sexuales.

La institucionalización del término se debe principalmente a la acción de organismos internacionales tales como Amnistía Internacional e ILGA. El desplazamiento semántico fue realizado por la primera organización a partir de su informe de 1999. En 2001, Amnistía Internacional sistematiza dicha asimilación entre el asesinato político, las ejecuciones extrajudiciales y los homicidios perpetuados en la esfera personal e intima por otros actores:

Sin embargo, la tortura y los malos tratos a manos de funcionarios públicos sólo es la punta del iceberg de la violencia dirigida contra gays y lesbianas. Para muchos, la experiencia más habitual de violencia es la que padecen en sus casas, escuelas y centros de trabajo, o en la calle. La tortura forma parte de un espectro más amplio de violencia; aunque los autores $\mathrm{y}$ escenarios varían, todas las formas de violencia homofóbica tienen en común la ignorancia y los prejuicios que alberga la sociedad y que se traducen en esta violencia, en la discriminación y la represión oficiales que la propician, y en la impunidad que la sostiene. [...]. Amnistía Internacional considera que los actos de violencia contra lesbianas, gays, bisexuales y transexuales en el hogar y en la comunidad constituyen tortura, de la que el Estado ha de responder [...]. (AMNISTÍA INTERNACIONAL, 2001, p. 16).

En 2001, ILGA (International Lesbian and Gay Association) incluye una serie de notas referentes a homicidios en el continente. En dicho informe, se incluyen varios perfiles de homicidios sin distinguirse los unos de los otros. A partir de entonces, se institucionalizó el término, de tal modo que fueron modificándose las legislaciones en todo el continente latinoamericano: en 2003, Uruguay incluyó un artículo en su Código Penal que castiga con hasta dieciocho meses de cárcel la 'Incitación al odio, desprecio o violencia' contra las minorías sexuales, mientras que en Colombia el odio homofóbico es un agravante desde 2007; al igual que en Nicaragua desde 2008 (CEJILCIPAC, 2010). En el Distrito Federal, la Asamblea local modificó el Código Penal para incluir el odio como agravante, aumentándose las penas cuando el móvil del delito o crimen esté vinculado con el prejuicio homofóbico.

Ahora bien, las recopilaciones del Grupo Gay de Bahía, los reportes de 'crímenes de odio' de la $\mathrm{CCCCOH}$ en México, así como los primeros registros en el Perú, junto con los informes de Amnistía Internacional o ILGA, fomentaron la generalización del concepto en el vocabulario de los promotores de los derechos humanos de las minorías sexuales, sin diferenciar con precisión los asesinatos anti-LGBT respeto de los crímenes de odio por homofobia. Esta noción, aparecida en Estados Unidos con el objetivo de precisar y tipificar en el sistema judicial los homicidios motivados por el prejuicio, se generalizó entonces a todo asesinato perpetuado en contra de una persona LGBT. En efecto, en Brasil, en México o en Perú, a menudo la orientación sexual de la víctima es 
el único criterio utilizado para incluir casos de homicidios en sus listas de crímenes de odio. Es decir, el concepto sirve para insistir sobre la aguda violencia que se ejerce sobre los cuerpos y las existencias trans, gays y lesbianas, pero no se explícita con rigor los criterios que permitan distinguir entre un crimen motivado por el prejuicio homofóbico, y un homicidio derivado de una riña, de un intento de robo, o de conflictos interpersonales. No existe ni se generó ningún debate científico alrededor del término y de sus usos: la noción de crimen de odio fue desdibujándose debido a una metodología imprecisa que confunde criterios de selección con características; identificación del asesinato por prejuicio con patrones recurrentes de homicidios antiLGBT. 'Odio', 'homofobia', además, son términos problemáticos para explicar la acción homicida de un varón gay o HSH contra su pareja; conllevan una reflexión que en parte desatiende el origen del problema, y poco dice de la discriminación cotidiana, de la violencia de género, que conducen a los asesinatos contra las minorías sexuales ${ }^{9}$.

\section{Criterios de Identificación y Selección de los Homicidios contra las Minorías Sexuales}

Para tratar de las violaciones del derecho a la vida padecidas por las minorías sexuales, el primer problema que se plantea estriba en la selección de los homicidios anti-LGBT, siendo la orientación, la práctica y la identidad sexuales, categorías invisibles y a menudo no asumidas por las propias víctimas antes de ser asesinadas, o no reconocidas por sus familiares y demás cercanos tras su muerte. Ahora bien, los universos de asesinatos registrados por los organismos de defensa de derechos humanos y grupos LGBT, son muy diversos y, a menudo, implícitos o imprecisos. Del mismo modo, los criterios de identificación de los crímenes orientados por el odio y la intolerancia son variados, lo que dificulta su distinción. Además, algunas organizaciones, tales como Colombia Diversa, el Grupo Gay de Bahía, la Alianza Lambda de Venezuela o el Movimiento de Integración y Liberación Homosexual (MOVILH) en Chile, entienden 'crimen' en el sentido de 'delito' o 'agresión', acercándose al sentido estadounidense de 'hate crime' y a la noción europea de 'delito de odio'; mientras que en de otros países los informes únicamente dan constancia de los homicidios perpetuados en contra de personas transexuales y travestis, pero no registran los demás crímenes contra las minorías sexuales. Es el caso de Bolivia, en donde las mujeres transexuales de la Red Trebol llaman a esos crímenes 'asesinatos trans impunes'; de Venezuela, en donde la Alianza Lambda registró únicamente las muertes en la vía pública de sexoservidoras trans; o de Honduras, en donde el golpe de Estado de 2009 desencadenó en matanzas de transexuales y travestis, en buena medida protagonizada por militares y policías.

Todas estas diferencias en los criterios, los universos estudiados, las categorías de análisis o las tipologías de crímenes producidas, dificultan la comparación intercontinental e imposibilitan la construcción de un concepto claro de 'crimen de odio por homofobia' en el contexto local y regional. La noción estadounidense del crimen de odio o prejuicio establecía una igualdad entre las distintas poblaciones victimadas por móviles ligados a la intolerancia $\mathrm{y}$ al odio como agravantes equivalentes en todas ellas (JANOFF, 2005); sin embargo, en América Latina, se aborda al crimen de odio por homofobia como un homicidio con unas características propias como homicidio, perdiéndose de vista la base principal de este tipo de crímenes: el prejuicio respecto de las sexualidades 
Tabla 1. Distincción entre asesinatos anti-LGBT y "crímenes de odio" o motivados por el prejuicio hacia las minorías sexuales en Informes de DDHH

\begin{tabular}{|c|c|c|c|}
\hline País/Ciudad & Referencia del Documento o Informe & $\begin{array}{l}\text { Uso del término y distincción del } \\
\text { "crimen de odio" }\end{array}$ & Universo de delitos / asesinatos \\
\hline \multirow{8}{*}{$\begin{array}{l}\text { América } \\
\text { Latina }\end{array}$} & Informe Rompamos el silencio, Amnistía Internacional (1994) & No usan el término "crimen de odio" & $\begin{array}{l}\text { Ejecuciones extrajudiciales y asesinatos derivados de } \\
\text { la tortura }\end{array}$ \\
\hline & Informe La Violencia al descubierto, IRCCLRA (1996) & No usan el término "crimen de odio" & $\begin{array}{l}\text { Ejecuciones extrajudiciales y asesinatos derivados de } \\
\text { la tortura }\end{array}$ \\
\hline & El derecho a la propia identidad, Aministía Internacional (1999) & No usan el término "crimen de odio" & $\begin{array}{l}\text { Ejecuciones extrajudiciales y asesinatos derivados de } \\
\text { la tortura }\end{array}$ \\
\hline & Informe de la Relatora Especial las Naciones Unidas (1999) & No usan el término "crimen de odio" & $\begin{array}{l}\text { Ejecuciones extrajudiciales y asesinatos derivados de } \\
\text { la tortura }\end{array}$ \\
\hline & $\begin{array}{l}\text { Informe Anual sobre Violaciones de DDHH 1998-1999/2000 } \\
\text { de ILGA (2001) }\end{array}$ & No usan el término "crimen de odio" & $\begin{array}{c}\text { Todos los asesinatos (confusión entre crímenes de } \\
\text { odio y otros) }\end{array}$ \\
\hline & $\begin{array}{l}\text { Crímenes de Odio, conspiración del silencio, Amnistía } \\
\text { Internacional (2001) }\end{array}$ & Lo usan, pero no distinguen & $\begin{array}{c}\text { Todos los asesinatos (confusión entre crímenes de } \\
\text { odio y otros) }\end{array}$ \\
\hline & $\begin{array}{c}\text { Informe Los derechos humanos y la OS e IG, Amnistía } \\
\text { Internacional (2004) }\end{array}$ & Lo usan, pero no distinguen & $\begin{array}{c}\text { Todos los asesinatos (confusión entre crímenes de } \\
\text { odio y otros) }\end{array}$ \\
\hline & $\begin{array}{c}\text { Observatorio Transgender Europe, presentación de los datos } \\
\text { actualizados (2010) }\end{array}$ & Lo usan, pero no distinguen & Asesinatos contra travestis y transexuales \\
\hline \multirow{2}{*}{ Argentina } & $\begin{array}{l}\text { Informes Violaciones a DDHH Minorías Sexuales de la CHA } \\
\qquad(1993-2002 / 2008)\end{array}$ & No usan el término "crimen de odio" & Todos los asesinatos \\
\hline & $\begin{array}{c}\text { Informe Vio laciones de la IGLHRC (2010) a 46e sesión } \\
\text { CEDAW (mujeres lesbianas/trans) }\end{array}$ & No usan el término "crimen de odio" & Abusos y malos tratos por agentes de la ley \\
\hline \multirow{2}{*}{ Bolivia } & $\begin{array}{l}\text { In forme Mujeres Trans, Travesti, Intersex de Bolivia para 40e } \\
\text { sesión CEDAW (2010) }\end{array}$ & No usan el término "crimen de odio" & Abusos y malos tratos por agentes de la ley \\
\hline & Informe Red Trans Trebol Bolivia y Heartland Alliance (2013) & No usan el término "crimen de odio" & Asesinatos contra travestis y trans \\
\hline \multirow{4}{*}{ Brasil } & Informe Grupo Gay de Bahía, 1963-2000 y 1999-2000 (2001) & Lo usan, pero no distinguen & Todos los asesinatos \\
\hline & Informe Grupo Gay de Bahía, 1963-1994 (1996) & Lo usan, pero no distinguen & $\begin{array}{l}\text { Todos los asesinatos (confusión entre crímenes de } \\
\text { odio y otros) }\end{array}$ \\
\hline & Informe de Asesinatos de 2004, Grupo Gay de Bahía (2005) & No usan el término "crimen de odio" & Todos los asesinatos \\
\hline & Informe Situación DDHH LGBT de ALGB (2012) & Lo usan, pero no distinguen & $\begin{array}{l}\text { Todos los asesinatos (confusión entre crímenes de } \\
\text { odio y outros) }\end{array}$ \\
\hline Chile & Informes Anuales, MOVILH (2002-2012) & Distinguen, con otro término & Asesinatos por OS e IG denunciados \\
\hline Colombia & $\begin{array}{l}\text { Informes Anuales DDHH LGBT, Colombia Diversa } \\
\qquad(2004-2011)\end{array}$ & Distinguen, con otro término & $\begin{array}{c}\text { Todos los asesinatos (distincción de crímenes por } \\
\text { prejuicio) }\end{array}$ \\
\hline Costa Rica & $\begin{array}{c}\text { Diagnóstico de crímenes de odio en Costa Rica, CEJIL-CIPAC } \\
(2010)\end{array}$ & Distinguen & $\begin{array}{l}\text { Todos los asesinatos (distincción de crímenes por } \\
\text { prejuicio) }\end{array}$ \\
\hline Cuba & Informe Observatorio LGBT Cuba años 2009-2010 (2011) & No usan el término "crimen de odio" & Abusos y malos tratos por agentes de la ley \\
\hline Ecuador & \begin{tabular}{|l|} 
La impunidad por homofobia, Fundación Ecuatoriana Equidad \\
$(2010)$
\end{tabular} & No usan el término "crimen de odio" & Todos los asesinatos \\
\hline \multirow[b]{2}{*}{ Guatemala } & $\begin{array}{l}\text { Informe Especial Guatemala, el rostro de la homofobia, } \\
\text { OASIS, 1996-2006 }\end{array}$ & No usan el término "crimen de odio" & \begin{tabular}{|c|}
$\begin{array}{c}\text { Ejecuciones extrajudiciales y asesinatos derivados de } \\
\text { la tortura }\end{array}$ \\
\end{tabular} \\
\hline & \begin{tabular}{|c|}
$\begin{array}{c}\text { Informe sombra sobre Violaciones a los DDHH de las personas } \\
\text { LGBT en Guatemala, Heartland Alliance, IGLHRC, } \\
\text { OTRANS, RED LACTRANS (2012) }\end{array}$ \\
\end{tabular} & No usan el término "crimen de odio" & $\begin{array}{c}\text { Violaciones a los DDHH, ejecuciones extrajudiciales } \\
\text { y algunos asesinatos }\end{array}$ \\
\hline \multirow[t]{2}{*}{ Honduras } & $\begin{array}{c}\text { Investigación sobre crímenes de odio, Asociación Arcoiris } \\
\text { Honduras y CIPRODEH (2009) }\end{array}$ & Lo usan, pero no distinguen & $\begin{array}{l}\text { Todos los asesinatos (confusión entre crímenes de } \\
\text { odio y otros) }\end{array}$ \\
\hline & Informe No Vales un centavo, Human Right Watch (2009) & No usan el término "crimen de odio" & Abusos y malos tratos por agentes de la ley \\
\hline \multirow{2}{*}{ México } & $\begin{array}{c}\text { Informe Especial sobre las Violaciones de DDHH y Delitos por } \\
\text { OS (CNDH, 2010) }\end{array}$ & No usan el término "crimen de odio" & Asesinatos por OS e IG denunciados \\
\hline & Informe de Crímenes de Odio en México (CCCCOH, 2009) & Lo usan, pero no distinguen & $\begin{array}{c}\text { Todos los asesinatos (confusión entre crímenes de } \\
\text { odio y otros) }\end{array}$ \\
\hline Nicaragua & $\begin{array}{l}\text { Diagnóstico sobre crímenes de odio por OS en Nicaragua } \\
\text { 2005-2009, CEPRESI (2009) }\end{array}$ & Lo usan, pero no distinguen & $\begin{array}{c}\text { Todos los asesinatos (confusión entre crímenes de } \\
\text { odio y otros) }\end{array}$ \\
\hline \multirow{3}{*}{ Perú } & $\begin{array}{l}\text { Informe de Situación de DDHH TLBG en el Perú 2005, } \\
\text { MHOL (2005) }\end{array}$ & Lo usan, pero no distinguen & $\begin{array}{l}\text { Todos los asesinatos (confusión entre crímenes de } \\
\text { odio y otros) }\end{array}$ \\
\hline & Raiz Diversidad Reporte Perú 2004 (2005) y 2009 (2010) & No usan el término "crimen de odio" & Todos los asesinatos \\
\hline & $\begin{array}{c}\text { Informe sobre la Situación de los DDHH TLGB en el Perú, } \\
\text { Red TLBG-PROMSEX (2008 a 2012) }\end{array}$ & Sí distinguen & Todos los asesinatos \\
\hline \multirow[t]{2}{*}{ EI Salvador } & $\begin{array}{l}\text { Informe El Salvador "Sistematización de los hechos 2009", } \\
\text { Alianza (2009) }\end{array}$ & Sí lo usan & $\begin{array}{l}\text { Ejecuciones extrajudiciales y asesinatos derivados de } \\
\text { la tortura }\end{array}$ \\
\hline & Informe Diversidad Sexual en El Salvador, IHRLC (2012) & Lo usan, pero no distinguen & Algunos asesinatos solamente \\
\hline
\end{tabular}


minoritarias. Como bien admiten los redactores del último informe costarricense:

Hace falta mayor construcción metodológica y mayor precisión en los datos de forma tal que las afirmaciones sobre los casos identificados con las características de los crímenes de odio se sustenten sobre una base empírica mucho más sólida. Es necesario tener claro las deficiencias de una metodología que busca elementos objetivos, pero que tiene como objeto de estudio una serie de acciones que acaecen sin un marco legal que establezca criterios objetivos para el abordaje adecuado (...)". (CIPAC, 2010, p. 7).

\section{Definición y Caracterización del Crimen de Odio}

$\mathrm{Si}$ bien varios informes latinoamericanos utilizan la expresión 'crimen de odio por homofobia' sin definirla de manera concreta y explícita, existe una constante en cuanto a las características que teóricamente reúne el crimen homofóbico: 1) la identidad sexogenérica de la víctima; 2) la saña con la cual el crimen fue ejecutado; 3) el móvil, relacionado con la orientación sexual e identidad de género de la persona asesinada, y a menudo inducido de la fuerza física desplegada para cometer el crimen. En varios países, ha bastado la presencia de alguna de estas características para seleccionar a los posibles 'crímenes de odio por homofobia', aún sin tener reunidos los demás elementos y se han obviado otros aspectos, tales como la falta de vinculo afectivo anterior al crimen, característica necesaria para identificar al crimen de odio (MONSIVÁIS, 1999). Es decir, se confundieron las características de los homicidios con los criterios de identificación de las víctimas LGBT, por un lado, y con los criterios de selección de aquellos crímenes motivados por el prejuicio y la homofobia, por otro.

Por ejemplo, el Colectivo Raíz (2004; 2005) y el MHOL (BRACAMONTE y ÁlVAREZ, 2006), en Perú, no distinguen entre los asesinatos anti-LGBT producidos por la violencia interpersonal, y las masacres, ejecuciones extrajudiciales y otras persecuciones institucionalizadas durante la década de los ochenta y principios de los noventa. Incluso registran algunos asesinatos de personas cuya orientación o identidad sexo-genérica se desconoce, sin tener información acerca del móvil, llegando a proporcionar estimaciones poco elaboradas de crímenes posiblemente perpetuados por odio: este salto se dio cuando el MHOL presentó su Informe Anual, en el cual se calculaba en 70 los crímenes de odio cometidos contra estas poblaciones durante el año $2005^{10}$ :

Los coeditores estiman que hay un subregistro de las denuncias legales sobre estos casos, también un subregistro de lo que reportan los medios, y finalmente un subregistro regional $[\ldots]$. Es por eso que se determinó que habrían (sic) cuatro casos más por cada uno de los encontrados, aunque no queda claro por qué exactamente cuatro y no otro número que se podría haber calculado o estimado - explica Olivera (2008, p. 49) en su análisis de los 'crímenes de odio' en el Perú.

En cambio, en los últimos informes del MOVILH en Chile; del Centro para la Prevención del Sida (CEPRESI) en Nicaragua; o de la Asociación Arco Iris y del Centro de Investigación y Promoción en Derechos Humanos (CIPRODEH) en Honduras, no dan constancia de todos los 
crímenes contra personas LGBT, sino que registran meramente los comprobados crímenes de odio por homofobia, llegando por tanto a proporcionar frecuencias mucho más bajas respecto de los informes mexicanos y brasileños, o en comparación con algunas estimaciones realizadas en Guatemala (Amigos contra el sida, 2010) y Perú. En Chile, se refieren únicamente a los "asesinatos por homofobia o transfobia" denunciados, registrando unos trece "asesinatos o denuncias por homicidios basados en la orientación sexual o la identidad de género" (MOVILH, 2008, p. 38) entre 2002 y 2007. En Colombia, distinguen claramente entre los homicidios ligados a la intolerancia y los demás homicidios, clasificados según el móvil. A los primeros Colombia Diversa (2008; 2010) los llama 'homicidios por prejuicio', mientras que los demás son clasificados como 'homicidios con otro móvil que el prejuicio', y 'homicidios sin información sobre el móvil'. Tras una metodología depurada de identificación, selección y clasificación cotejando distintas fuentes, los abogados de Colombia Diversa no sólo comprueban, pues, la orientación sexo-genérica de la víctima, sino también la existencia del prejuicio homofóbico. Igualmente, en su diagnóstico de crímenes de odio de Costa Rica, los investigadores del CEJIL y del CIPAC (2010) distinguen entre distintos tipos de homicidios según si el móvil está ligado o no a la homofobia, y presentan la información de manera separada, evidenciando que los crímenes de odio suelen ser más violentos que los demás homicidios perpetuados contra personas LGBT.

\section{La Selección de Casos en México: la saña como criterio}

En México, para identificar los crímenes de odio cometidos en contra de las minorías sexuales, la $\mathrm{CCCCOH}$ estableció tres 'indicadores': en primer lugar, la forma del asesinato, la cual sigue un mismo patrón: "cadáver desnudo, con manos y pies atados, golpeado, huellas de tortura, apuñalado o estrangulado", según indica Fernando del Collado (2007, p. 38); en segundo lugar, la redacción de la nota: "el periodista nos suele informar de si la persona era homosexual. En el caso de hombres, alude al hecho de que la víctima vivía solo, con frecuencia visitado únicamente por hombres, o que se trata de un individuo "de costumbres raras" (COLLADO, ibidem), y finalmente, por las declaraciones de los policías en el momento de encontrar el cuerpo, quienes describen dichos homicidios como consecuencias de "pasiones entre homosexuales". No obstante, desde finales de los años noventa los informes publicados por la $\mathrm{CCCCOH}$ insisten en los rasgos violentos de aquellos crímenes, simbolizados éstos por el número de acuchilladas o de golpes, el uso de la tortura, o las huellas de asfixia y estrangulamiento, los cuales representarían tanto indicios de la identidad $\mathrm{u}$ orientación sexo-genérica de la víctima como indicadores del prejuicio u odio homofóbico del victimario. En efecto, para la $\mathrm{CCCCOH,} \mathrm{la}$ brutalidad, en dichos homicidios, "no deja lugar a dudas para considerar[los] dentro de la categoría de crímenes por odio", dado que la "gran mayoría de las víctimas fue hallada asesinada con extrema violencia y saña, lo que refleja la necesidad psicológica del victimario no sólo de infligir un daño a la víctima, sino de castigarlo hasta el exterminio" (CCCCOH, 2005, p. 37). La violencia se convirtió entonces en un criterio, a veces único, para la selección de casos de crímenes ligados a la homofobia, e incluso, un indicio de la orientación o identidad sexogenérica de la víctima.

Ahora bien, al retomar el listado de crímenes en el Distrito Federal de la $\mathrm{CCCCOH}$ para capturar la información 
contenida en las notas de prensa, constaté que para muchos supuestos asesinatos contra personas LGBT, no teníamos ninguna información acerca de la identidad sexogenérica de la víctima en la nota que había servido para identificar el caso, y en muy pocas notas teníamos suficientes datos para clasificar los casos entre los crímenes de odio. Tampoco se establecieron reglas metodológicas de cotejo de la información con los datos de organismos judiciales y de medicina legal. Así pues, en rigor los datos proporcionados por la $\mathrm{CCCCOH}$ representan (a) homicidios de personas LBGT y HSH referenciados por los medios escritos de comunicación y, entre éstos, (b) crímenes cuyo móvil es la homofobia, la intolerancia y el odio hacia la orientación sexo-genérica de la víctima, además de (c) homicidios contra personas susceptibles de ser homosexuales, bisexuales o lesbianas.

Los sucesivos equipos de la $\mathrm{CCCCOH}$ seleccionaron los homicidios susceptibles de ser crímenes anti-LGBT por la saña con la cual habían sido perpetuados, partiéndose de la hipótesis de que los llamados crímenes de odio eran por naturaleza especialmente violentos. Ahora bien, se seleccionaron también homicidios de personas que no pertenecían a las minorías sexuales: ajustes de cuentas entre bandas, riñas y ejecuciones que podemos vincular con el contexto de aumento de la criminalidad y de la corrupción policiaca en la ciudad de México a mediados de los años 1990, en un contexto de crisis social agudísima. Al problema de escasez de información sobre la orientación sexual e identidad de género de las víctimas, la cual no se recoge de forma sistemática en la prensa, se suma el sesgo ligado a las fuentes empleadas para analizar los homicidios cometidos en contra de las minorías sexuales: en efecto, la mayoría de las veces aquélla se obtiene de periódicos sensacionalistas tales como La Prensa y El Gráfico, los cuales se centran en hechos muy violentos que tienden a reforzar los tópicos sobre las personas LGBT.

El origen de la representación violenta del homicidio anti-LGBT se halla en dicha prensa amarillista, la cual alimentó los discursos alarmistas de los activistas. Noel Alvarado, un reportero de La Prensa, quien publicó alrededor del $60 \%$ de las notas de nuestra base (BOIVIN, 2013b), refiere en una entrevista (2012) que la hipótesis policiaca sobre la orientación sexual de la víctima a menudo no es confirmada, o es utilizada para darle más fuerza a la nota. Igualmente, según subraya Collado en otra entrevista (2012), en buena parte la redacción de la nota roja se guía por las palabras textuales de los informes policiales: a menudo, los reporteros no se desplazan al lugar de los hechos, las escenas de los 'crímenes homosexuales' se describen desde despachos lejanos, reproduciéndose los prejuicios homofóbicos. Guiado por éstos, el discurso periodístico y la falta de análisis acerca de las causas que llevan a dicha violencia vincula el 'odio' y la saña con la (posible) orientación sexual de la víctima, enfocándose meramente en la dimensión interpersonal del homicidio:

Cuando llegas a un escenario y encuentras desorden en una casa, automáticamente te viene a la mente que hay robo [...]; hay ocasiones en que te vas dando cuenta que el robo pasa a ser un segundo término, y que realmente [...] en ese tipo de homicidio entra la cuestión pasional o la cuestión de venganza [...]. En el caso de una ejecución, desde el primer momento en que llegas te das cuenta que no hay ni ropa y que van directo a la persona. $O$ sea, no hay robo, no hay forzadura de chapas, te das cuenta que por fuerza tuvo que haber sido alguien cercano, alguien 
a quien la víctima le permitió el acceso. Entonces ahí vas empezando a diferenciar, te das cuenta que hay mucha violencia, hay mucha saña, hay cierto odio específico [...]. La violencia que se comete contra la víctima es a consecuencia de que en ese momento el victimario saca toda su [...] todo su odio y todo su coraje que trae contra la víctima. (Entrevista con Noel Alvarado, 2012).

No obstante, si bien por lo general los asesinatos descritos en la prensa mexicana son muy violentos, no representan al conjunto de crímenes perpetuados contra las minorías sexuales: por una parte, se cometen crímenes menos violentos y morbosos, y por ende, menos identificables, o difícilmente aprovechables por la prensa sensacionalista; mientras que, por otra, seguramente existan homicidios que sí son vinculados al odio y al prejuicio homofóbicos, y por éstos mismos silenciados por los cercanos y familiares, e inadvertidos por los medios de comunicación. Sin embargo, el sesgo vinculado a la sobre-representación de víctimas asesinadas en circunstancias extremadamente violentas no se tiene en cuenta en la literatura, pese a la insistencia de la misma en describir la orientación homofóbica del discurso mediático.

\section{Las Características de las Víctimas y de Ios Homicidios ${ }^{11}$}

Tras revisar las notas de prensa de la $\mathrm{CCCCOH}$, se hizo una nueva búsqueda en $\mathrm{El}$ Excélsior, El Universal, El Gráfico y Reforma para los casos 'dudosos'12 y de víctimas referenciadas en las listas de la $\mathrm{CCCCOH}$ para los cuales no teníamos notas de prensa. En la mayoría de los casos 'dudosos' para los cuales encontramos notas de seguimiento o nuevas notas en otros periódicos, el crimen no estaba relacionado con el prejuicio; en muchos no se pudo comprobar que la víctima fuera LGBT o $\mathrm{HSH}$, y en varios casos se confirmó que la víctima era heterosexual. Asimismo, se descartaron los casos repetidos y los homicidios cometidos en otras entidades de la República Mexicana que habían sido introducidos por error en el listado de la $\mathrm{CCCCOH}$. Finalmente, hemos identificado nuevos casos mediante una nueva búsqueda en archivos digitales de La Prensa, Reforma y El Universal, en crónicas de la Brigada Callejera en Apoyo a la Mujer 'Elisa Martínez' (2013), y se cotejó la información con los datos del Observatorio de Asesinatos Trans (TGEU, 2013).

Posteriormente, con el objetivo de crear un perfil típico de los asesinatos contra las minorías sexuales en la ciudad de México, a partir de tales casos 'seguros' se hizo un análisis descriptivo de sus características. Salvo algunas pocas excepciones, en esta primera fase se seleccionaron únicamente los casos para los cuales la(s) nota(s) que describe(n) el caso registra(n) un 'crimen pasional' entre personas del mismo sexo, y/o menciona(n) que la víctima era lesbiana, gay, transgénero; o que mantenía relaciones homosexuales.

Según los resultados obtenidos en esta primera fase, las víctimas se caracterizan por pertenecer a grupos en edades económicamente activas: más de un tercio de la muestra pertenece al grupo de 16-24 años, el $12 \%$ tiene entre 25 y 34 años, y otro $25 \%$ entre 35 y 44 . Una proporción importante de las víctimas son profesionistas, directores de empresas y personal eclesiástico, quienes representan el $36 \%$ de nuestra muestra, mientras que las demás trabajan en comercios, restaurantes y bares $(15 \%)$, son trabajadores sexuales $(18 \%)$ o inactivos.

Por otro lado, el $58 \%$ de los casos seguros 
es asesinado en su vivienda, el $20 \%$ en la vía pública y el $13 \%$ en cuartos de hotel. Las ejecuciones se realizan por arma blanca en un tercio de los casos, otro $27 \%$ de las víctimas muere a consecuencia de golpes; la tercera causa de muerte siendo la asfixia, el estrangulamiento o el ahorcamiento; es decir, causas y formas de muerte que implican tanto la cercanía física como la falta de premeditación y preparación del asesinato. Los resultados obtenidos permiten diferenciar los crímenes cometidos contra las minorías sexuales respecto de los demás homicidios que se cometen en México D.F., ya que, desde 1995, los hombres asesinados en esta ciudad son esencialmente varones jóvenes y pobres, quienes mueren principalmente en la vía pública y por armas de fuego, rasgos que se oponen a las características más típicas de los homicidios contra los varones HSH (Tablas 2 y 3 ).

\begin{tabular}{|c|c|c|c|}
\hline \multicolumn{4}{|c|}{ Lugar del homicidio en el DF según el sexo, INEGI, 1995-2010 } \\
\hline Lugar del homicidio & Varones & Mujeres & Total \\
\hline Hogar & $9 \%$ & $38 \%$ & $13 \%$ \\
\hline Vía pública & $73 \%$ & $40 \%$ & $69 \%$ \\
\hline Centro de recreo & $1 \%$ & $1 \%$ & $1 \%$ \\
\hline Lugar de trabajo & $5 \%$ & $4 \%$ & $5 \%$ \\
\hline Otros y no especificados & $12 \%$ & $17 \%$ & $13 \%$ \\
\hline Total & $100 \%(14.485)$ & $100 \%(1.962)$ & $100 \%(16.449)$ \\
\hline \multicolumn{4}{|c|}{ Homicidios LGBTT en México D.F. según el lugar y el sexo de la víctima, 1995-2010 } \\
\hline Lugar del homicidio & HSH y trans* & Trans y travestis & Total \\
\hline Hogar & $66 \%$ & $25 \%$ & $59 \%$ \\
\hline Vía Pública & $12 \%$ & $55 \%$ & $19 \%$ \\
\hline Hoteles y comercios & $12 \%$ & $20 \%$ & $13 \%$ \\
\hline Lugar de trabajo & $4 \%$ & $0 \%$ & $3 \%$ \\
\hline Otros lugares, fiestas privadas & $6 \%$ & $0 \%$ & $5 \%$ \\
\hline Total & $100 \%(100)$ & $100 \%(20)$ & $100 \%(120)$ \\
\hline
\end{tabular}

Tabla 3. Causa principal de la muerte según la orientación sexo-genérica de la víctima o sexo en México D.F., 1995-2012

\begin{tabular}{|l|c|c|c|}
\hline Causa principal de la muerte & $\begin{array}{c}\text { Gay, bise- } \\
\text { xual, HSH }\end{array}$ & $\begin{array}{c}\text { Travesti, } \\
\text { transexual }\end{array}$ & $\begin{array}{c}\text { Varones en } \\
\text { D.F. }\end{array}$ \\
\hline Acuchillado, apuñalado & $34 \%$ & $25 \%$ & $15 \%$ \\
Asfixia, estrangulamiento, ahorcamiento & $29 \%$ & $13 \%$ & $4 \%$ \\
Golpeado, torturado o degollado & $28 \%$ & $21 \%$ & $3 \%$ \\
Baleado & $10 \%$ & $25 \%$ & $63 \%$ \\
Atropellado y arrojado y otras causas & $0 \%$ & $17 \%$ & $15 \%$ \\
\hline \multicolumn{2}{|c|}{91 (100\%) } & 24 (100\%) & 15425 \\
Total & $100 \%)$ \\
\hline Fuente: Boivin, Base de Casos de Homicidios LGBTT y HSH, México D.F., 1995-2012 \\
(casos seguros), INEGI, Homicidios de Varones, 1995-2011, según Clasificación Interna- \\
\hline
\end{tabular}


Una vez creado este perfil, para reintroducir los casos 'dudosos' susceptibles de ser homicidios anti-gay/HSH, seleccionamos las variables que más caracterizan a tales crímenes (grupo de edad, ocupación, forma de residencia de la víctima, tipo de lugar y colonia del homicidio, causa de muerte), re-incorporándose los casos 'dudosos' de varones que correspondieran en al menos tres de aquellas seis variables al perfil típico de víctima HSH, lo que nos llevó a re-introducir 30 casos, es decir, un $12 \%$ de la muestra inicial. Según la información recogida, en México D.F., desde 1995 hasta 2012, se dieron 180 casos ('seguros' y 'dudosos reintroducidos') de homicidios contra personas pertenecientes a las minorías sexuales. (Tabla 4).

Nuestros resultados matizan el argumento de la extrema violencia física del crimen antiLGBT: el 25\% de las víctimas (casos seguros) se encontraron con huellas de tortura, el 6\% sufrió alguna agresión sexual antes de morir; un $25 \%$ de los cuerpos fue hallado atado, amarrado y maniatado. La violencia física y las huellas de tortura no representan criterios fiables de identificación de los crímenes contra las minorías sexuales: al eliminar los casos de personas cuya orientación o prácticas sexuales no han sido identificadas o cuyas notas de seguimiento permiten comprobar que no se trataba de personas LGBT, disminuye la proporción de víctimas torturadas y asesinadas con mucha saña. Tales hallazgos se vinculan directamente con el error de selección al que nos referíamos anteriormente, al haberse integrado en los listados de homicidios LGBT casos particularmente violentos de personas que no pertenecían a las minorías sexuales; $y$, por el uso de una fuente sensacionalista, casos de homicidios antiLGBT especialmente violentos. Este tipo de selección conllevó una marcada circularidad en la argumentación: los crímenes de odio son hipotéticamente violentos, por lo que los homicidios muy violentos son, intuitivamente, asesinatos perpetuados en contra de personas LGBT cuya saña refleja el odio homofóbico, y que por lo tanto se deben integrar en listados de asesinatos de "crímenes de odio", confirmándose finalmente la importancia de la saña en los análisis de los resultados obtenidos.

\begin{tabular}{|c|c|c|c|}
\hline \multicolumn{4}{|c|}{$\begin{array}{l}\text { Tabla 4. Fases de recuento en Base de Casos de Homici- } \\
\text { dios LGBT y HSH en México D.F., 1995-2012 }\end{array}$} \\
\hline \multicolumn{2}{|c|}{ Fases del recuento } & Casos & $\%$ del total \\
\hline \multirow{3}{*}{ Fase1 } & $\overline{\text { Seguro }}$ & 150 & $61 \%$ \\
\hline & Dudoso o descartado & 98 & $40 \%$ \\
\hline & Total & 248 & $100 \%$ \\
\hline \multirow{4}{*}{ Fase2 } & Seguro & 150 & $61 \%$ \\
\hline & Dudoso & 52 & $21 \%$ \\
\hline & Descartado & 46 & $19 \%$ \\
\hline & Total & 248 & $100 \%$ \\
\hline \multirow{4}{*}{$\begin{array}{l}\text { Selección } \\
\text { final }\end{array}$} & Seguro & 150 & $61 \%$ \\
\hline & Dudoso o descartado & 68 & $27 \%$ \\
\hline & Dudoso re-introducido & 30 & $12 \%$ \\
\hline & Total & 248 & $100 \%$ \\
\hline
\end{tabular}




\section{Del Crimen Pasional al Crimen de Odio}

Una vez determinada nuestra muestra de asesinatos anti-LGBT, es necesario disociar los homicidios cometidos por prejuicio $\mathrm{O}$ intolerancia respecto de los demás asesinatos. Una primera distinción es realizada por la prensa, según la cual el $51 \%$ de los casos de homicidios anti-LGBT y HSH cometidos entre 1996 y 2012 con información sobre el móvil ( $\mathrm{n}=102)$, es motivado por la 'venganza pasional', en tanto que el $12 \%$ se asocia con el asalto o el robo, y el 9\% con riñas y ajustes de cuentas. El odio homofóbico aparece en el $11 \%$ de los casos y en otro $11 \%$, el responsable alega que actuó en defensa o venganza de un acoso sexual o violación previa.

Para cambiar las prácticas policiales o judiciales y modificar los discursos periodísticos acerca de los crímenes perpetuados en contra de las minorías sexuales, los militantes y académicos han rechazado la definición de tales homicidios como 'crímenes pasionales', es decir, derivados de la emoción violenta e incontrolable, ya que como tales son penalizados con menor severidad. Según ya denunciaba la $\mathrm{CCCCOH}$ en su primer Informe de crímenes, los asesinatos antiLGBT representarían en efecto "un problema social, alimentado por una sociedad que educa a sus ciudadanos de manera intolerante y con base en estereotipos (...), alimentan el morbo y la percepción de que sólo son crímenes pasionales entre homosexuales, pretendiendo evadir con ella la responsabilidad que la misma sociedad tiene como generadora del odio homofóbico." (Citado por COLLADO, 2007, p. 52). Por consiguiente, en oposición a aquella definición del homicidio anti-LGBT, que criminaliza a la víctima y rebaja la imputabilidad del crimen, los activistas procuraron evidenciar que el nivel de violencia y dolor impuestos a la víctima informaban del grado de homofobia contenido en el acto delictivo, de tal modo que describieron a los victimarios como personas heterosexuales intolerantes $y$ prejuiciosas, negando así la existencia de crímenes ocurridos entre personas pertenecientes a las minorías sexuales por razones no ligadas a la homofobia, y perdiendo interés por las características de los victimarios e implicados en aquellos crímenes.

Mas sin embargo las fuentes utilizadas y las estadísticas producidas a partir de ellas, en raras ocasiones permiten demostrar que dichos homicidios hayan sido motivados por la orientación sexual de la víctima. Por otro lado, la información sobre el seguimiento judicial del caso y, por ende, acerca del móvil del homicidio, es de acceso restringido en México, y meramente las familias o sus mandatarios legales pueden realizar el trámite de solicitud de la averiguación previa al Instituto de Acceso a la Información Pública y Protección de Datos Personales. Por lo tanto, a menudo es imposible acceder a otra versión de los hechos que no sea la expuesta en la prensa, lo que nos impide distinguir entre homicidios calificados por el odio homofóbico y los asesinatos motivados por los celos o el robo, o consecuentes de riñas y atracos, es decir, no ligados directamente con la intolerancia de quien(es) comete(n) el crimen. Así pues, si bien los activistas son críticos con sus fuentes, siguen siendo muy dependientes de sus registros: se hallan en una disyuntiva circular al otorgar tanto peso a la nota roja, mientras que a la vez pretenden rechazar las representaciones estereotipadas de la misma. Para romper con la definición de estos homicidios impuesta por sus fuentes, sin mayor información sobre el caso, los militantes acaban integrando en listas de crímenes homofóbicos los asesinatos anti-LGBT y HSH perpetuados por otros 
motivos, conocidos y desconocidos. Si bien es cierto que no todos los crímenes denominados 'pasionales' por la prensa y su fuente policial constituyen homicidios emocionales, tampoco podemos afirmar que todos los asesinatos registrados como tales en los medios informativos sean crímenes de odio por homofobia. ${ }^{13}$

\section{Discreción, Estigma, Alcohol: de la Homofobia a la Vulnerabilidad}

Según constatábamos, los homicidios cometidos en contra de los varones gays, HSH y bisexuales en el Distrito Federal, se distinguen de los demás asesinatos por la forma y la causa de la muerte; el lugar del homicidio y las características demográficas de la víctima. Estos rasgos están directamente asociados con el aislamiento y con la confianza que deposita la víctima en el victimario, la cual permite la cercanía física y explica el uso frecuente de armas improvisadas en el crimen: entre los casos "seguros" y re-introducidos, el 63\% de las víctimas $(\mathrm{n}=84)$ conocía a $\mathrm{su}(\mathrm{s})$ victimarios previamente al crimen (no se incluyen las relaciones de ligue ocasional), y en al menos un $37 \%$ de los casos, la víctima se encontraba desnuda o semidesnuda. Los homicidios ejecutados en contra las minorías sexuales no se vincularían tanto con el prejuicio, sino, por un lado, con los factores de vulnerabilidad ligados a las formas de socialización y encuentro sexual de las minorías sexuales y, por otro lado, la inseguridad que implica el trabajo sexual así como el chantaje de los policías y agentes de la trata de personas y de la explotación sexual.

En efecto, es necesario contextualizar los homicidios contra las minorías sexuales en el marco de 'Una cultura del homicidio, del uso de armas de fuego, del consumo de alcohol y drogas' (CRUZ, 2010), aunado a la alta proporción de jóvenes sin acceso a la educación y al trabajo, a la impunidad generalizada y al contexto más amplio de violencia social y urbana. En $27 \%$ de los casos 'seguros' de homicidios anti-LGBT, ha sido comprobada la presencia o influencia de alcohol, y el $65 \%$ se cometió durante el fin de semana, mientras que el $87,5 \%$ ocurrió de noche. Asimismo, los victimarios y sospechosos suelen ser de clases más bajas que las víctimas, y mantienen con las víctimas relaciones de dependencia económica, en condiciones de desigualdad y jerarquía social: eran sus empleados (5\%), o ejercían trabajo sexual para la víctima. Una proporción alta de los homicidios contra las minorías sexuales ocurre en las colonias de mayor concentración comercial o residencial LGBT: $35 \%$ de 164 casos fueron hallados en zonas de residencia gay, $18 \%$ en zonas de ligue o de comercios LGBT, mientras que el $49 \%$ de los cuerpos se encontraron en la calle $\mathrm{y}$ hoteles ubicados en zonas de tolerancia y sexoservicio.

Los homicidios anti-LGBT son fruto de la estigmatización y de la segregación, que llevan a las minorías sexuales a interiorizar, callar y reproducir la violencia. La necesidad de esconderse determina a las minorías sexuales a vivir situaciones de riesgo (BOIVIN, 2013c; BOIVIN, 2014). La misma discreción observada por la víctima acerca de sus prácticas y gustos sexuales se transforma en un gran factor de vulnerabilidad e impunidad, ya que en este contexto de silencio y ocultamiento, es improbable que el vecindario o la familia quieran aportar datos acerca de los sospechosos o de las circunstancias del homicidio. Así pues, muchos de los asesinatos perpetuados contra las minorías sexuales involucran de forma indirecta la violencia homofóbica. La literatura regional describe con detalle las situaciones de vulnerabilidad que experimentan las minorías sexuales, remitiéndose repetidamente al contexto de 
homofobia cultural, social e institucional, así como a las formas de sociabilidad y vinculación sexual condicionadas por el ocultamiento y el silencio; bases culturales sobre las cuales descansan los homicidios anti-LGBT y que fomentan su impunidad. Tanto en México como en otros países latinoamericanos, los autores subrayan que el problema de los homicidios anti-LGBT estriba en la falta de investigación judicial, el prejuicio y el desprecio de las autoridades judiciales hacia las minorías sexuales, así como en la impunidad que este contexto de discriminación institucional y homofobia genera:

La vulnerabilidad de la población transexual mostró su cara más dura en 2007, pues tres personas fueron brutalmente asesinadas cuando ejercían el comercio sexual [...]. Es indiscutible que la mayoría de los homicidios se dieron en ambientes hostiles, como son los vinculados al comercio sexual, pero igual de claro es que las mujeres transexuales ejercen ese oficio producto de la falta de oportunidades laborales y educacionales, lo que las vuelve vulnerables socialmente y las expone al peligro. (MOVILH, 2008, p. 38).

Los crímenes de odio por homofobia son la manifestación más acabada de la homofobia social, que es un fenómeno encarnado en nuestra cultura (...). Los asesinos, pocas veces son aprehendidos y sentenciados, pero son apenas la parte más visible del problema: todos y todas participamos en la comisión de estos asesinatos en la medida en que reproducimos la homofobia social (Efraín
RODRÍGUEZ, 2010, p. 61).

Descubierto el crimen, lo habitual es la indiferencia judicial que prolonga la indiferencia social. Ni los agentes judiciales a los que les corresponde la investigación, ni el Ministerio Público, ni las Procuradurías, ni (por miedo o acoso policial) las parejas o los amigos de las víctimas, reaccionan con la indignación debida, inexistente en el caso de las autoridades. (MONSIVÁIS, en MUÑOZ, 2010, p. 28 -29).

Salvador Cruz (2002) muestra por ejemplo que el crimen de odio es un reflejo de la homofobia social. Para ilustrar su argumento, se apoya en el caso de un profesor e investigador de la UNAM, asesinado en circunstancias no aclaradas, 'al parecer por razones de homofobia o políticas'. Como bien confiesan las palabras del investigador, no importa tanto sí la homofobia orientó la conducta homicida del victimario, dado que ésta 'se manifiesta en las dificultades que enfrenta la familia para el reconocimiento del crimen homofóbico y la decisión de iniciar, o no, un juicio legal para el esclarecimiento del homicidio, así como la inoperatividad e ineficacia de los sistemas legales y judiciales en los casos de asesinatos a homosexuales'. (CRUZ, 2002). Así pues, el 'crimen de odio' contra las minorías sexuales es definido por la homofobia del contexto social y cultural, basado en el silencio, la indiferencia y la impunidad, y no tanto por el prejuicio y la intolerancia del victimario. La violencia física y simbólica que trasparecen en muchos de los crímenes perpetuados contra minorías sexuales, entonces, no nos remitiría al odio homofóbico, sino a un contexto social que circunscribe la acción de aquéllas en círculos de violencia social y precariedad. 
El Concepto del Crimen de Odio por Homofobia en América

Latina. Datos y discursos acerca de los homicidios contra las minorías sexuales: el ejemplo de México

\section{La Homofobia Institucional y el Uso de la Tortura}

Entre los casos 'seguros' del Distrito Federal, solo se identificaron el $18 \%$ de los victimarios en los casos de crímenes antitrans, y el $48 \%$ para los varones $\mathrm{HSH}$. $\mathrm{La}$ impunidad se constituye en una de las principales características del crimen antiLGBT, en especial en los asesinatos cometidos contra las transexuales trabajadoras sexuales, en los cuales representaría un 'eslabón del círculo de estigma, discriminación y violación a los Derechos Humanos', explican las mujeres del Centro de Atención a las Identidades Trans (CAIT, 2013). El seguimiento judicial dado a los homicidios contra las minorías sexuales suele estar jaloneado de prejuicios homofóbicos, impidiendo la procuración de justicia; y las penas impuestas por los homicidios ejecutados en contra de las minorías sexuales suelen ser menores a las previstas por el Código Penal (COLLADO, 2007).

Pero la impunidad no sólo viene ligada al desinterés, sino, también, a la alta participación de actores públicos en las violaciones a los derechos humanos padecidas por las minorías sexuales y trabajadoras del sexo. En el Distrito Federal, los reportes señalan así que las instituciones gubernamentales de justicia y seguridad pública son los principales autores de los abusos y atropellos de sus derechos humanos. (CNDH, 2010; CDHDF, 2008; 2009; 2013). El 29\% de los victimarios cuyas ocupaciones son conocidas $(n=64)$ ejercían como policías, o habían sido empleados de las fuerzas de seguridad pública. Así pues, a la negligencia de los servicios judiciales en el seguimiento de las investigaciones, a menudo se suma la participación de los mismos agentes quienes las discriminan, extorsionan, violan sexualmente, y hasta asesinan. Protegidos por la cultura del silencio y el clóset, sus abusos de poder no están sometidos a ninguna restricción ni sanción. El clima de silencio, discriminación y estigma no sólo implica la falta de denuncia, sino que genera a la vez un contexto propicio para la violación de los derechos humanos por los propios agentes de la ley. El Informe especial sobre las violaciones de los derechos humanos de las personas LGBT en el Distrito Federal 20062007 (CDHDF, 2008) expuso con detalle cómo los policías y agentes del Ministerio Público hostigan y agreden sexualmente a los menores de edad y jóvenes gays o bisexuales y HSH, quienes son rechazados o abandonados por sus familias en edades tempranas, y a menudo se encuentran en situación de calle o de extrema pobreza.

Los crímenes perpetuados en contra de las transexuales, travestis y trabajadora/es sexuales en espacios públicos y hoteles cuyos autores son desconocidos, tienen como probables responsables a los propios policías y militares, quienes suelen usar métodos de tortura para obtener confesiones falsas, y frecuentemente se hallan implicados en el tráfico sexual de personas, como se denunció desde la Relatoría especial sobre las ejecuciones extrajudiciales y sumarias y el derecho a la vida de las minorías sexuales (1999). Remiten a un contexto de abuso de poder y limpieza social, y a un patrón conocido de violencia, que empieza desde la detención arbitraria y a menudo acaba con la muerte. (AMNISTÍA INTERNACIONAL, 1999; 2001). Las personas transgénero que trabajan en la calle están sobreexpuestas a situaciones de violencia policial, muy distintas al odio personalizado que los activistas retratan del homicida homofóbico, 'ligue' casual que abusa de la confianza de su víctima para robarla $\mathrm{y}$, si se resiste, asesinarla.

En este sentido, es necesario distinguir entre los homicidios contra personas que 
ejercen el trabajo sexual en la calle, cuyo modus operandi los asimila a ejecuciones extrajudiciales efectuadas por militares y policías; y el segundo patrón, más frecuentemente perpetuado en la casa de la víctima por personas que abusan de su confianza. Este segundo de tipo de crimen afecta principalmente a los gays asumidos de clases medias y altas, mientras que el primero está asociado a la corrupción policial, al tráfico de sexual de personas, a la violencia institucional, incluso política, ejercida en contra de las minorías sexuales. Este segundo patrón había sido identificado desde los años 1970 como un crimen político por las organizaciones en las que dichas prácticas suelen terminar.

A principios de los años 1980, la asimilación del $\mathrm{VIH} /$ sida con las minorías sexuales va a desencadenar una mayor visibilidad de éstas y, al mismo tiempo, una mayor estigmatización. Ésta se inscribió en prácticas y en leyes, en bandos de policías y códigos municipales, criminalizando a las personas LGBT y a las trabajadoras sexuales. El objetivo de limpieza social se reafirmó en ejecuciones realizadas por el Ejército y la policía, en México como en el resto de América Latina. A principios de los años noventa, en Buenos Aires, en Montevideo, en Ciudad de México, esta violencia institucional se intensificó en los lugares de trabajo sexual y zonas de concentración comercial LGBT, sumándose a un conjunto de medidas públicas, actitudes de rechazo y agresiones físicas. Los informes de la CHA (1998) documentaron por ejemplo varias series de asesinatos contra las minorías sexuales directamente vinculadas con las violencias cometidas de forma cotidiana por los agentes de la policía local. El trabajo de Sempol (2013) a partir de dichos reportes evidencia que, desde finales de los años 1980, a menudo los asesinatos se cometieron en contra de los travestis y las transexuales políticamente más activas, o quienes han denunciado o amenazaron con denunciar las agresiones y las detenciones arbitrarias de los agentes. En Colombia, en el Perú, en Honduras, Nicaragua y Bolivia, los conflictos armados y la inestabilidad política agravaron la situación: los militares y grupos paramilitares persiguieron, violaron $\mathrm{y}$ masacraron decenas de personas LGBT (COLOMBIA DIVERSA, 2010; BRACAMONTE y ÁLVAREZ, 2006; CHA; 1998). Hoy en día, estas prácticas siguen siendo aplicadas, infundiendo miedo entre las sexoservidoras. En el informe publicado por la Red Lactrans (2013), las entrevistadas colombianas atestiguan por ejemplo de ejecuciones frecuentes realizadas por militares y policías, quienes torturan y matan a las transexuales que hayan denunciado sus maltratos.

En México, los militares y los policías fueron directamente involucrados en varias series de crímenes perpetuados contra gays y travestis a principios de los años 1990. Entre junio de 1991 y febrero de 1993, entre 15 y 25 hombres gay, travestis y transexuales fueron asesinados en Tuxtla Gutiérrez, Chiapas. En su mayoría fueron baleados con armas del mismo calibre, pertenecientes a la policía. Amnistía Internacional (1994), junto con varios centros locales de defensa de los derechos humanos de Chiapas, denunciaron la participación de la policía estatal, subrayando que la mayoría de los asesinatos registrados evidenciaban un patrón similar, asociado a la participación de policías. Los cuerpos fueron abandonados en espacios baldíos, y a menudo las víctimas fueron transportadas después de haber sido contactadas en otros lugares. En paralelo, en la ciudad de México se multiplican las redadas contra las personas transexuales, travestis y HSH quienes trabajan en la calle, $\mathrm{y}$ en algunas ocasiones coinciden las fechas de los operativos policiales en los lugares de 
trabajo sexual, con el hallazgo en las cercanías, el día siguiente, del cuerpo sin vida de algún travestí. Por ejemplo, en una nota del Excélsior, titulada 'Retiraron de la Vía Pública a 20 homosexuales en Iztapalapa', informan que, en un primer operativo realizado por la policía delegacional, se aplicó una multa de 921 pesos a cada uno de los 23 sexoservidores, condenándoles a 36 horas de arresto. Se anuncia además que se realizarán operativos similares de forma metódica. El día siguiente se encuentra muerto, 'vestido de mujer', Fidel Vázquez Juárez, en su domicilio cercano a los lugares de comercio sexual objetivos del acoso policiaco. Los homicidios contra los y las trabajadoras sexuales se desplazan junto con las zonas de relativa tolerancia hacia el sexoservicio: de Buenavista a la Calzada de Tlalpán, y por ésta hasta Coyoacán.

Asimismo, cabe mencionar la probable participación de militares en los homicidios de travestis y gays en las colonias del viejo centro histórico de la ciudad de México, alrededor de la Plaza de Garibaldi, en donde estaban resurgiendo cantinas y bares de homosocialización tales como El 14, los cuales atraían tanto a la población LGBT local como a jóvenes militares en estancia antes de partir para el Estado de Chiapas. La saña empleada para ejecutar estos crímenes, la presencia de huellas de tortura física, señalan que las víctimas fueron asesinadas por militares o, en su caso, policías y (ex) agentes judiciales. Algunos de estos homicidios consisten asesinatos políticos, de activistas o de personas susceptibles de denunciar el hostigamiento, la extorsión, así como la participación de las autoridades en la trata de niños y adultos. Representan asesinatos que dan continuidad al chantaje policiaco al ir reiterando un mensaje de amenaza hacia todo el grupo: exigiéndole alta discreción en el espacio público, so pena de ser agredida, amenazada, secuestrada o muerta por las mismas autoridades:

...se puede observar que el modus operandi de los servidores públicos señalados como responsables de tortura, en general, sigue el mismo patrón: la detención suele derivar de una supuesta denuncia anónima de aparentes actos de flagrancia en la comisión de un delito (...). El mayor número de casos de tortura se presenta durante la detención y mientras la persona se halla bajo la custodia de la autoridad que la realizó, además de que las víctimas son detenidas por servidores públicos que, en la gran mayoría de los casos, no se identifican, o bien, tratan de no dejar evidencia alguna de su participación, lo cual facilita la impunidad (...). Los lugares en donde se cometen las torturas pueden ser los propios domicilios de las víctimas, los medios de transporte en que son trasladadas, las oficinas de las corporaciones policiacas, los hoteles, los parajes solitarios e, incluso, las denominadas "casas de seguridad". Entre los métodos de tortura denunciados ante esta Comisión Nacional se reconocen (...), traumatismos causados por golpes dados con las manos, los pies y objetos contundentes, así como golpes dados con tablas en los glúteos y en los oídos; asfixia o ahogamiento con métodos como aplicación de agua simple o así como la colocación de bolsas de plástico en la cabeza; descargas eléctricas en los testículos, el recto, los pies, las piernas y el tórax; quemaduras con cigarrillos, fierros calientes y escapes de motor; 
lesiones permanentes como heridas de arma de fuego; violencia sexual; suspensión de los pies, los dedos o el cuello, ataduras en los pies y exposición a sustancias químicas. (CNDH, 2005, p. 2).

\section{Algunas Conclusiones}

Los activistas han denunciado que los homicidios anti-LGBT representan el resultado y la expresión de la violencia cotidiana hacia las minorías sexuales. Las estadísticas acerca de este tipo de homicidio permitirían evidenciar el nivel de homofobia cultural que achaca a la sociedad mexicana. Ahora bien, la mayor documentación de estos crímenes y su denuncia es el producto de una problematización pública de los delitos cometidos en agravio de las minorías sexuales; es decir, in fine, la manifestación de un mayor reconocimiento de las identidades sexuales periféricas por los Estados latinoamericanos. Así, la construcción social y discursiva del 'crimen de odio' ha venido edificando la necesidad de una mayor 'tipificación' y sanción de los crímenes basados en el prejuicio hacia la orientación sexo-genérica de la víctima, 'tipificación' que vendría siendo realizada por los servicios del SEMEFO, de Justicia, o por la misma policía.

No obstante, la noción jurídica original no sirve para nombrar y entender la violencia y la vulnerabilidad ligadas al estigma y a los prejuicios homofóbicos que anteceden, legitiman y producen los homicidios contra las minorías sexuales; generando confusión a la hora de cuantificar la consecuencia homicida del prejuicio y de la intolerancia o de realizar análisis de tipo comparativo o diacrónico.

El desplazamiento semántico desde 'los asesinatos políticos' y ejecuciones extrajudiciales hacia el llamado 'crimen de odio por homofobia', se complementa por un cambio en el tipo de denuncia que se realiza.

Es decir, por una parte, la denuncia de todos los asesinatos de las personas transexuales, travestis, lesbianas y gays, de su alta frecuencia e impunidad y, por otra parte, la transformación del sistema judicial para que éste reconozca y sancione con más imputabilidad los crímenes que hayan sido efectivamente motivados por el prejuicio y la intolerancia hacía las minorías sexuales.

Según constatamos, antes de la aparición del concepto estadounidense 'crimen de odio por homofobia', los promotores de derechos humanos LGBT denunciaban la impunidad de los homicidios perpetuados en contra de las minorías sexuales, asesinatos que se hallaban en continuidad con un conjunto de violencias institucionalizadas cometidas, parte de ellas, por agentes públicos. En cambio, al centrarse en el 'odio homofóbico' de los crímenes, los militantes se olvidaron de lo fundamental, esto es, que la violencia homicida ejercida contra las minorías sexuales y reproduce por la falta de investigación, los errores de interpretación judicial, las violaciones de los derechos humanos presentes a lo largo de los procesos judiciales que involucran a las minorías sexuales y, por último, la impunidad que los discursos prejuiciosos de la policía y las prácticas discriminatorias de las instituciones de procuración de justicia, implican y conllevan.

Las estrategias de tipificación que se quieren implementar, al ser acompañadas de la asociación sistemática entre el mayor registro de la orientación sexual de la víctima, y la realizada entre ésta y el prejuicio homofóbico supuesto de los victimarios, precisamente se encaminan hacia una mayor criminalización de éstos, quienes, al igual que sus víctimas si no más (BOIVIN, en prensa), han padecido la dominación masculina, el estigma y la discriminación social a lo largo de sus trayectorias individuales, 
reproduciéndose así en la sentencia la injusticia social, al considerarse como agravante lo que en realidad representa el peso del prejuicio heterosexista de las instituciones y actores sociales. Por lo tanto, el discurso alarmista de los militantes y académicos psicologiza, patologiza, a través de las nociones de odio y homofobia, el comportamiento del victimario, y en este sentido individualiza la condena, consolidando las bases de la conformación de identidades sociales desde el aparato médicojudicial (FOUCAULT, 1999). La 'tipificación' del odio homofóbico, confundida con la tarea más amplia de investigar los asesinatos contra las minorías sexuales, se convierte en fabulosa herramienta de identificación y constitución de las mismas, dando continuidad a la dialéctica siempre renovada de represión y liberación de la sexualidad y de sus formas de visibilización.

1 HSH o 'Hombres que tienen sexo con hombres', es un término utilizado desde los años 80 por algunos antropólogos estadunidenses. Fue retomado por ONUSIDA a mediados de los años 90 en el contexto de las políticas públicas epidemiológicas. En México, dicha categoría fue introducida por CONASIDA por estas fechas.

2 Según mencionan los investigadores del CEJIL y del CIPAC (2010, p. 8), el término fue introducido en la legislación norteamericana con dos variaciones: "Por un lado, se utiliza el hate crime, o crimen de odio, que, por lo general, se observa, principalmente, en leyes federales. Por otra parte, se usa el bias crime, o crimen por prejuicio, [que] se advierte, por lo general, en la jurisprudencia estatal. La generalización en el uso del término "hate crime" frente al "bias crime", la definieron los medios de comunicación".

3 Según Ibarra, "Un delito de odio puede ser cualquier delito realizado contra personas, colectivos sociales y/o sus bienes, cuando la víctima, los bienes o el objetivo del delito hayan sido seleccionados por prejuicios o animadversión a su condición social, por vinculación, pertenencia o relación con un grupo social definido por su origen nacional, étnico o racial, su idioma, color, religión, identidad, género, [...], orientación sexual [...]. Estos delitos envían a todos los miembros del grupo al que pertenece la víctima un potente mensaje de amenaza". (Movimiento contra la intolerancia, 2006, p. 5).

4 Efrain Cruz García, travestí chiapaneco trabajador sexual, fue humillado, torturado y atropellado por una camioneta dirigida por paramilitares en la Calzada de Tlalpán de la ciudad de México, en presencia de numerosos vecinos y testigos. Entre los activistas gays asesinados figura Francisco Estrada, quien fue ejecutado en 1992 junto con otros dos amigos en la casa de uno de ellos - se supone, por militares.

5 Sin usar ningún término específico, los primeros grupos gays mexicanos, en especial el Frente Homosexual de Acción Revolucionaria (FHAR), ya habían llevado a cabo labores de recolección de notas de prensa en los años 70 y principios de los 80, documentado agresiones y asesinatos contra personas LGBT. Los archivos del Centro de Información y Documentación de las Homosexualidades en México "Ignacio Álvarez" (CIDHOM), antes alojado en el Colectivo Sol, A.C., hoy forman parte del Fondo I del Centro Académico por la Memoria de Nuestra América (CAMeNA), de la Universidad Autónoma de la Ciudad de México (UACM).

$6 \quad$ Marta Lamas es fundadora y directora de la revista Debate feminista, es investigadora en el Programa de Estudios Universitarios de Género (PUEG). Carlos Bonfil es crítico de cine en La Jornada y amigo de varios ex-miembros de Lambda, un grupo gay de los años 80. Alejandro Brito es cofundador de Letra $\mathrm{S}$, organización que publica un suplemento mensual sobre sexualidad, salud sexual y VIH/sida en La Jornada.

7 MHOL, 'Recuento del 31 de Mayo', en: http://www.ciudadaniasx.org/?20-Peru-Recuento-del31-de-mayo, 2012.

8 Véase Blumenfeld (1992), quien distinguía entre la homofobia interpersonal y social, la homofobia cultural y la homofobia institucional.

9 Según Luis Ortiz y Granados Cosme (2003), el concepto de 'homofobia' no describe fielmente el contexto de discriminación contra los varones noheterosexuales, ligado al sistema de género. En este artículo, usaré el término "homofobia" para remitirme 
a todas las formas de violencia simbólica, psicológica y física que se genera por prejuicio hacia las minorías sexuales y las expresiones de género no minoritarias; la palabra "transfobia" para referirme al miedo, al odio, a la falta de aceptación y a la intolerancia hacia dichas expresiones en personas tránsgenero.

10 El mismo tipo de cálculo se efectuó en México: se estimó, a partir del Informe de 1996 de Brasil, que cada víctima representaba a otros dos o tres asesinatos "invisibles" más.

11 En otro trabajo por publicar, estudio con más detenimiento las características de las víctimas, de los victimarios, y las circunstancias de los homicidios, definiendo patrones de asesinatos anti-LGBT.

12 Los casos 'dudosos' son aquéllos para los cuales no sabemos si la víctima era una persona LGBT o HSH, o para las cuales sólo tuvimos acceso a notas de recopilación de casos del periódico Reforma; mientras que los casos 'seguros' son todos aquellos para los cuales la(s) nota(s) de prensa refieren la orientación sexo-genérica de la víctima o, en su caso, 'crímenes pasionales' entre personas del mismo sexo. También existen asesinatos de personas cuya orientación sexo-genérica no aparece en la nota de prensa, pero ésta era conocida o pública. Algunas veces la consulta del expediente judicial confirmó la orientación no-heterosexual de la víctima, aunque, por discreción o cualquier otro motivo, ésta no se apuntara en la nota periodística, como por ejemplo en el caso del sociólogo Francisco Gómez Jara. Finalmente, confirmamos de forma individual algunos casos: por ejemplo, se fueron añadiendo asesinatos en hoteles por desconocidos, en especial en lugares cercanos a zonas de prostitución y de operativos policiacos llevados a cabo en dichas zonas.

13 En otro lugar, desarrollo el método utilizado para establecer una nueva clasificación de los homicidios anti-LGBT a partir del nivel de violencia física y simbólica, y de los distintos agravantes. El prejuicio homofóbico a menudo se solapa con conflictos en el orden simbólico y social, siendo el homicidio anti-gay una muestra, también, de la violencia masculina. Por ejemplo, El Sádico, quien, junto con su cómplice, secuestró y asesinó a varios jóvenes gay, fue motivado por la mayor facilidad (según su percepción) de asegurarse la confianza de una varón gay que una mujer para llevar a cabo sus secuestros (Averiguación Previa, COY-3T3/2046/0512). La información acerca del pasado y de la situación de precariedad laboral del victimario, ex militar y médico, esclarece el móvil.

14 El SEMEFO es el servicio de medicina forense de las Procuradurías estatales de Justicia en México. Es encargado de conservar los cadáveres hasta su identificación y reclamación por parte de los cercanos de la víctima.

\section{Referências}

ACCIÓN CIUDADANA CONTRA EL SIDA (ACCSI). II Informe sobre Homofobia, Violencia e Impunidad contra la Comunidad Lesbiana, Gay, Transexual y Bisexual en la República Bolivariana de Venezuela. Caracas: ACCSI, 2009.

AMIGOS CONTRA EL SIDA. Caligrafía de la memoria. Historias en cuerpos que se leen. Ciudad de Guatemala: Amigos contra el Sida, 2010.

AMNISTÍA INTERNACIONAL. Asesinatos de gays en Chiapas: continúa la impunidad. Madrid: Editorial Amnistía Internacional (EDAI), 1994.

AMNISTÍA

INTERNACIONAL.

Rompamos el silencio. Madrid: EDAI, 1994.

AMNISTÍA INTERNACIONAL. Crímenes de odio, la conspiración del silencio. Tortura y malos tratos basados en la identidad sexual, Editorial Amnistía Internacional (EDAI), 2001. http://amnistiainternacional.org/publicacione s/23-crimenes-de-odio-conspiracion-desilencio-tortura-y-malos-tratos-basados-enla-identidad-sexual.html

BALLERO, Martín Jaime. Informe anual sobre derechos humanos de personas trans, lesbianas, gays y bisexuales en el Perú 2008. Lima: Red Peruana de TLGB, PROMSEX, 2008. 
BEST, Joel. Uso y abuso de las estadísticas. La distorsión en la percepción pública de los problemas sociales y políticos. Editorial Cuatro Vientos, Santiago, 2009.

BONFIL, Carlos. Crímenes de Odio en México. La urgencia de legislar. Letra S. Sexualidad, Salud, Sida, n. 130, s/p, 2007.

BOIVIN, Renaud René. Base de Notas de Homicidios LGBT y HSH en México D.F., 1995-2012, 7 de enero de 2013a.

BOIVIN. Movilidad, inseguridad vulnerabilidad, $y$ el derecho a la ciudad de las minorías sexuales. Dfensor, Comisión de Derechos Humanos del Distrito Federal (CDHDF), México D.F., marzo de 2013b

BOIVIN, Renaud René. "La ciudad de la homofobia. Discriminación y violencia hacia las minorías sexuales en las urbes mexicanas". Revista Latino-americana de Geografia e Género, Ponta Grossa, vol. 5, n.1, 2014. Disponível em: http://www.revistas2.uepg.br/index.php/rlagg /article/view/5406

BOIVIN, Renaud René. Base de Casos de Homicidios, 5 de diciembre de 2012.

BRACAMONTE, Jorge; ALVAREZ CHÁVEZ, Roland (Eds.). Informe Anual 2005. Situación de los Derechos Humanos de Lesbianas, Trans, Gays y Bisexuales en el Perú. Lima: Movimiento Homosexual de Lima (MHOL), 2006.

BRIGADA CALLEJERA DE LA MUJER EN APOYO A LA MUJER "ELISA MÁRTINEZ". Crónicas periodísticas de la Red Mexicana de Trabajadoras del Sexo 1997-2012, 2013. Disponível em : $<$ http://brigadaac.mayfirst.org/Cronicas-dela-Red-Mexicana-de-Trabajo-Sexual>.
Consultado em: 21/02/2015.

BROWN, David. Investigación sobre crímenes de odio contra las personas LGBT en Honduras 2005-2009. Tegucigalpa: Asociación Arcoiris de Honduras; Centro de Investigación y Promoción de los Derechos Humanos (CIPRODEH), 2009. Disponível em: $<$ http://www.portalsida.org/repos/Informe_Cr imenes_de_Odio_Final $\% 5 \mathrm{~B} 1 \% 5 \mathrm{D} \% 5 \mathrm{~B} 1 \% 5$ D.pdf>. Consultado em: 21/02/2015.

$\mathrm{CCCCOH}$. Informe de Crímenes de Odio por Homofobia. México 1995-2008. Resultados Preliminares. México D.F.: Letra S, Sida, Cultura y Vida Cotidiana A.C., 2009. Disponível em: $<$ http://es.scribd.com/doc/40332169/INFOR ME-DE-CRI\%CC\%81MENES-DE-ODIOPOR-HOMOFOBIA-ME\%CC\%81XICO1995-2008>. Consultado em: 21/02/2015.

\section{COMISIÓN DE DERECHOS HUMANOS} DEL DISTRITO FEDERAL (CDHDF). Informe especial sobre violaciones a los derechos humanos por orientación o preferencia sexual e identidad o expresión de género en el Distrito Federal 2007-2008. México D.F.: CDHDF, 2008. Disponível em: $<$ http://directorio.cdhdf.org.mx/libros/2008/1 0/informe_lgbt.pdf $>$. Consultado em: 21/02/2015.

CDHDF. Recomendación 15/2009. México D.F.: CDHDF, 2009.

CDHDF. Trata de personas y violencia sexual en el Distrito Federal. México D.F.: CDHDF, 2010.

CDHDF. Informe sobre la situación de los derechos humanos de las personas LGBT en la ciudad de México 2012. Aportes desde la Comisión de Derechos Humanos 
del Distrito Federal, 2013.

COMISIÓN NACIONAL DE LOS DERECHOS HUMANOS (CNDH). Informe especial sobre Violaciones a los Derechos Humanos y Delitos cometidos por Homofobia, México D.F.: CNDH, 2010. Disponível

em:

$<$ http://www.cndh.org.mx/sites/all/fuentes/do cumentos/informes/especiales/2010_homofo bia.pdf $>$. Consultado em: 21/02/2015.

CENTRO DE APOYO A LAS IDENTIDADES TRANS (CAIT). Informe de Crímenes de Mujeres Trans en México, Invisibilidad=Impunidad. México D.F.: CAIT, 2013. Disponível em: $<$ http://centroapoyoidentidadestrans.blogspot .mx/2013/02/informe-crimenes-de-mujerestrans-en.html $>$. Consultado em: 21/02/2015.

CENTRO PARA LA EDUCACIÓN Y LA PREVENCIÓN DEL SIDA. Diagnóstico sobre los crímenes de odio por motivos de orientación sexual en contra de las lesbianas, gays $y$ transexuales en Nicaragua. Managua, 2009.

CEJIL-CIPAC. Diagnóstico sobre los crímenes motivados por la orientación sexual e identidad de género en Costa Rica. CEJIL, 2010.

COLECTIVO RAÍZ. Reporte Anual sobre Derechos Humanos de personas lesbianas, gays, trans y bisexuales en el Perú: 2004. Lima: Raíz 2.0. Boletín Diversidad, 2005.

COMITÉ INTERECLESIAL DE DERECHOS HUMANOS EN AMÉRICA LATINA (ICCHRLA). La violencia al descubierto. Represión contra lesbianas y gays en América Latina, ICCHRLA, 1996.

COLOMBIA DIVERSA. Derechos humanos de lesbianas gays y transgenistas en Colombia 2006-2007, Bogotá: Colombia Diversa. 2008.

COLOMBIA DIVERSA. Todos los deberes, todos los derechos. Situación de los Derechos humanos de lesbianas gays y transgenistas en Colombia 2008-2009, Bogotá: Colombia Diversa. 2010.

COMUNIDAD

HOMOSEXUAL

ARGENTINA (CHA). Informe Anual Sobre Violaciones a los Derechos Humanos y Civiles en la Republica Argentina Basadas en la Orientación Sexual de las Personas y de las Personas que viven con VIH/SIDA, 1998, [1993]. Disponível em: $<$ http://www.cha.org.ar/docs/info_historico.d oc>. Consultado em: 21/02/2015.

CRUZ SIERRA, Salvador. Homofobia y masculinidad. El Cotidiano, vol.18, n.113, p. $8-14,2002$.

CRUZ SIERRA, Salvador. Homicidios masculinos en Ciudad Juárez. Costos de las masculinidades subordinadas. Frontera Norte, vol.23, n.46, p. 239 - 262, 2011.

COLLADO (del), Fernando. Homofobia. Odio, crimen y justicia, 1995-2005, México D.F.: Tusquets, 2007.

FOUCAULT, Michel. Los anormales. México D.F.: Fondo de Cultura Económica, 1999.

ILGA. Informe Anual sobre la situación de Derechos Humanos de GLBT, 19981999/2000, 2001.

JACOBS, James B; POTTER, Kimberly. Hate crimes. Criminal law and identity politics. New York: Oxford University Press, 2001. 
JANOFF, Victor Douglas. Pink blood. Homophobic violence in Canada. Toronto: University of Toronto Press Incorporated, 2005.

LUGO GARFÍAS, María Elena, HERNÁNDEZ FORCADA, Ricardo. Algunas notas sobre la tortura en México. México D.F.: CNDH, 2004.

MOTT, Luiz Roberto. Epidemic of Hate. Violations of the Human Rights of Gay Men, Lesbians, and Travestites in Brazil. Salvador de Bahía: Grupo Gay de Bahía, 1996.

MOTT, Luiz Roberto; CERQUEIRA, Marcelo. Causa Mortis: homophobia. Salvador de Bahía: Grupo Gay de Bahía, 2001.

MOVILH (Movimiento de Integración y Liberación Homosexual). VI Informe Anual Derechos Humanos Minorías Sexuales Chilenas (Hechos 2007). Santiago: MOVILH, 2008. Disponível em: $<$ http://www.movilh.cl/documentos/VIINFORMEANUAL-ddhh-2007.pdf $>$.

Consultado em: 12/02/2015.

MOVILH. VIII Informe Anual Derechos Humanos de la Diversidad Sexual Chilena (Hechos 2009). Santiago: MOVILH. 2010. Disponível em: $<$ http://www.movilh.cl/documentacion/movil h-informe-derechos-humanos-2009.pdf $>$. Consultado em: 21/01/2015.

MOVILH (2011). IX Informe Anual Derechos Humanos de la Diversidad Sexual Chilena (Hechos 2010). Santiago: MOVILH. Disponível em: $<$ http://www.movilh.cl/documentacion/IXInforme-anual-ddhh-2010-movilh.pdf $>$. Consultado em: 21/02/2015.
MONTOYA HERRERA, Orlando. La impunidad por homofobia $y$ discriminación que sufre la comunidad GLBT en América Latina y Caribe. Quito: Fundación Ecuatoriana Equidad, 2010. Disponível em: $<$ http://hivaidsclearinghouse.unesco.org/searc $\mathrm{h} /$ resources/santiago impunidad por_homof obia_- ecuador.pdfs. Consultado em: $21 / 0 \overline{2} / \overline{2} 015$.

MOVIMIENTO CONTRA LA INTOLERANCIA. La lucha contra los Delitos de Odio en Europa. Una visión general de Estadísticas, Legislación e Iniciativas Nacionales (Materiales

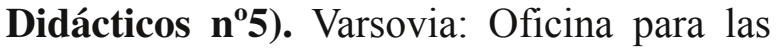
Instituciones Democráticas y los Derechos Humanos (ODIHR), 2006.

MIANO BORRUSO, HERNÁNDEZ CHÁVEZ Juan-Jacobo. Archivo Histórico del Movimiento Homosexual en México. México D.F.: $\quad$ CIDHOM/Colectivo Sol/ENAH, 2004.

MONSIVAIS, Carlos. La homofobia y sus prejuicios. En: MUÑOZ RUBIO, Julio. Homofobia. Laberinto de la ignorancia. UNAM, Centro de Investigaciones Interdisciplinarias en Ciencias y Humanidades: México D.F., 2010, p. 23 - 32.

OLIVERA FUENTE, Crisstian Manuel. Crímenes de odio por orientación sexual o identidad de género en Perú. En VV.AA.: EI derecho como campo de lucha. Lima, DEMUS, 2008.

ORTIZ HERNÁNFEZ, Luis; GRANADOS COSME, José Arturo. Violencia hacia bisexuales, lesbianas y homosexuales de la Ciudad de México. Revista Mexicana de Sociología, n. 2, p. 265 - 303, 2002. 
El Concepto del Crimen de Odio por Homofobia en América

Latina. Datos y discursos acerca de los homicidios contra las

minorías sexuales: el ejemplo de México

RODRÍGUEZ, Efraín. Un crimen de odio por homofobia en Ciudad Juárez. El Cotidiano, n.164, p. 61 - 67, 2010.

SEMPOL, Diego. La violencia policial hacia la disidencia sexual en la postdictadura, Ponencia presentada en el Seminario Permanente sobre Historia reciente. Montevideo: GEIPAR, 2013. Disponível em: $<$ http://www.geipar.udelar.edu.uy/wpcontent/uploads/2013/06/SEMPOL-DiegoViolencia-policial-hacia-disidencia-sexualGEIPAR-2006131.pdf>. Consultado em: 21/02/2015.

TRANSGENDER EUROPE (TGEU). Observatorio de Asesinatos Trans. 2013. Disponível em: <http://www.transrespecttransphobia.org/es_ES/tvt-project/tmmresults.htm>. Consultado em: 21/02/2015. .

Recebido em 10 de setembro de 2014. Aceito em 05 de dezembro de 2014. 